\title{
ARTICLE
}

\section{Introduction of “Guideline for radiation shielding evaluation of transport casks by Monte Carlo method” -the outline of guideline draft-}

\author{
Mitsufumi Asami $^{\mathrm{a}^{*}}$, Hiroaki Taniuchi ${ }^{\mathrm{b}}$, Tsutomu Matsumoto ${ }^{\mathrm{c}}$, Yukio Sakamoto ${ }^{\mathrm{d}}$ \\ and Hiroki Sakamotob \\ ${ }^{a}$ National Maritime Research Institute, 6-38-1 Shinkawa, Mitaka, Tokyo, 181-0004, Japan; ${ }^{b}$ Transnuclear Tokyo, 1-18-6, Shinbashi, \\ Minato-ku, Tokyo, 105-0004, Japan; ${ }^{c}$ OCL Corporation, 2-11-6 Nishishinbashi, Minato-ku, Tokyo, 105-0003, Japan; ${ }^{d}$ ATOX \\ Corporation, 1201, Takada, Kashiwa, Chiba, 277-0861, Japan
}

Guidelines for radiation shielding evaluation by Monte Carlo method was designed and developed for practical radiation shielding for radioactive material transport casks. The guidelines consist of current technical advancement on estimating the dose equivalent rates around the surface of a transport cask. The guidelines could be useful to validate the procedure and the results of radiation shielding analyses for transport casks.

Keywords: radioactive material transport cask; Monte Carlo method; shielding design; dose equivalent rate; Guideline

\section{Introduction}

In Japan, adopting the shielding analyzes for safety evaluation method of radiation shielding for the casks by Monte Carlo method is coming under review. It has been examined to take Monte Carlo method into account for safety evaluation of radiation shielding for casks. In order to comply with the request from the stakeholder of the transport cask industry, a special committee was established under the Atomic Energy Society of Japan, which addresses advancement of radiation shielding safety evaluation by Monte Carlo method for radioactive material transport casks. The committee is composed of experts from the university, Japan Atomic Energy Agency, industry groups of nuclear fuel transporting, nuclear fuel transport cask engineers and nuclear plant engineers. Summarizing the discussion in the committee, we intend to develop the guideline for radiation shielding evaluation of transport casks by Monte Carlo method.

This guideline consists of current technical status on estimating the dose equivalent rate around the surface of a transport cask, considerations in the safety evaluation and the current status of legal affairs for the purpose of applying the radiation shielding analyses based on Mote Carlo method. Furthermore, the guideline is useful for both the applicant and regulatory agency relevant to the transport casks; the applicant for the transport casks can show to the regulatory agency the shielding ability of the

*Corresponding author. Email: asami@nmri.go.jp transport casks designed based on the reasonable evaluation approach. The regulatory agencies, on the other hand, can review the calculation in the written application in a proper manner and validate it. Additionally, the shielding designers of the radioactive material transport cask utilize this guideline; they can design the transport cask more practically based on the adequate ways. The guideline has two unique features: one is that the calculation process is illustrated, which can be used to calculate the radiation shielding properly. Another feature is that the shielding benchmarks calculations for transport casks by Monte Carlo method are attached, which is based on the previously performed dose rate measurements of the casks. By comparison between measurements and the calculations for the transport casks, accuracy level of the shielding calculation can be determined.

\section{Guideline for radiation shielding evaluation of transport casks by Monte Carlo method}

\subsection{Scope of the guideline}

The guidelines is intended for the exclusive casks for transport or the dry metal casks for storage and transport of spent nuclear fuels. Specific recommendations are made regarding radiation attenuation calculations, shielding design and standards of documentation for the use of Monte Carlo method. The guideline provides guidance to regulatory agency, electric companies, and architect-engineers who are responsible for the shielding 
design of radioactive transport casks. The draft does not consider sources of radiation other than those associated with radioactive transport casks. It also excludes considerations of economic aspects of shielding design other than the choice of analytical scheme based on Monte Carlo method. The document discusses methods of analysis and the shielding input data appropriate to Monte Carlo method.

\subsection{The organization of the guideline}

On the purpose of this guideline, valuable annexes are provided as follows: (1) Terms and definitions which are used for explanation of shielding calculation technique based on Monte Carlo method. Terms and definitions are provided to assure correct understanding of selected terms as they are used in the draft. A number of terms are used in the draft as defined in several textbooks on the subject of radiation shielding based on Monte Carlo method. (2) Shielding benchmark calculations for radiation penetration experiment with geometric configuration of the transport cask. This annex gives applications of Monte Carlo method, including the dry transport casks and wet transport casks problems.

\subsection{Regulation requirements}

Radiation shielding performance of the transport casks with nuclear spent fuels must be maintained under the transport condition of the regulations for the safe transport of radioactive material. In the IAEA regulation of spent fuel transport packages with respect to shielding safety, the radiation level under normal transport shall not exceed $2.0 \mathrm{mSv} / \mathrm{h}$ at any point on the external surface of the transport cask, and $0.1 \mathrm{mSv} / \mathrm{h}$ at $2 \mathrm{~m}$ from the external surface of the conveyance. ${ }^{[1]}$ The radiation level under accident conditions of transport, on the other hand, shall not exceed $10 \mathrm{mSv} / \mathrm{h}$ at $1 \mathrm{~m}$ from the external surface of the transport cask. ${ }^{[1]}$ Additionally, under Japanese regulation, the radiation level under routine conditions of transport shall not exceed $0.1 \mathrm{mSv} / \mathrm{h}$ at 1 $\mathrm{m}$ from the external surface of the transport cask. The design of radiation shielding for transport casks is performed on the basis of this criterion.

\subsection{The shield design for casks}

Following items are necessary to design transport casks for radiation shielding to meet the regulation ${ }^{[2]}$ :

- specifications on radioactive contents,

- source intensity of radioactive contents,

- evaluation technique of radiation shielding, and

- criterion for the design of radiation shielding.

In the present study, all the computational process of the shielding calculation based on Monte Carlo method was classified into some processes, which is useful for assessing calculation. As a result, it was found that the following process is required to apply shielding calculation technique based on Monte Carlo method to transport casks:

(a) modeling of geometric configuration, (b) approach in the use of the variance reduction techniques applicable to shielding configurations,

(c) approach in the use of the estimator(tally) applicable to shielding configurations,

(d) quality of random number generator for Monte Carlo method, and

(e) evaluation of calculation result and statistics.

\subsection{The comprehensive calculation procedure}

The ultimate goal of this study is to illustrate the comprehensive calculation procedure, which helps us to perform the calculation properly. The calculation processes which was divided into five categories in the foregoing section 2.4. are illustrated by Figures 1-5. These flow charts are the essence of the guideline (draft). Especially, these flow charts consist of the quality of random number generator for Monte Carlo method and the evaluation of the calculation result and statistics. We revisit the evaluation of the result and statistics in more detail, section 2.6.. By the following these process, the applicant can perform the radiation shielding calculation properly and the regulatory agency can check whether the calculation performed by the applicant is proper or not.

Geometric configuration of the transport cask which is used for the Monte Carlo calculation is not very particular to the other calculation techniques. For more detail modeling, homogenization of region or treatment of dimension is taken with caution. Meanwhile, the setting of variance reduction and the choice of the estimator are peculiar to the Monte Carlo calculation.

The important statistic generated by the calculation is the "figure of merit." This is defined as

$$
F O M \equiv \frac{1}{R^{2} T}
$$

where $T$ is the simulation time, which is proportional to the number of histories run, and $R$ is the relative error. For different simulations of the same problem, the simulation with the largest FOM is preferred since it requires the least time or produces a specified relative error.

\subsection{Accuracy and precision of calculation results}

With Monte Carlo method and its various variance reduction techniques, it is possible to produce calculation results that, while very precise, are not very accurate. Technically, precision is the uncertainty in the tally mean caused by the statistical fluctuations in the individual scores of the simulated histories. ${ }^{[3]} \mathrm{By}$ contrast, accuracy is a measure of how close the tally mean is to the true physical quantity being estimated. ${ }^{[3]}$ The difference between the true value and the expectation value of the simulation tally is called the systematic error, an important quantity but one that is seldom known.

Nuclear data and geometric configuration, which was used to perform the radiation shielding calculation, should be accurate for the high integrity evaluation. On the premise of this, the statistical checks with the 
calculation should pass the provisional standard with which various calculation codes are specified. The existence of the benchmark experiments which are applicable to the condition of the source intensity, the geometric configuration and material components enables the validation by the calculation based on Monte Carlo method. For this, this guideline includes the shielding benchmark calculations.

In many cases, however, there are not enough experiments which are performed by same configuration to which we want to calculate. In order to determine statistical validity of the calculation result, the statistical check which is served with output has to be passed, that is to say, the calculation has high accuracy.

Meanwhile, the accuracy of calculation should be evaluated by the result of benchmark experiment. However, for the determination of the accuracy of the result, following evaluation can be substitute for the result of benchmark experiment: 1) The dose equivalent rate is distributed continuously around the cask; 2) Same result is available regardless of the different use of biasing method.

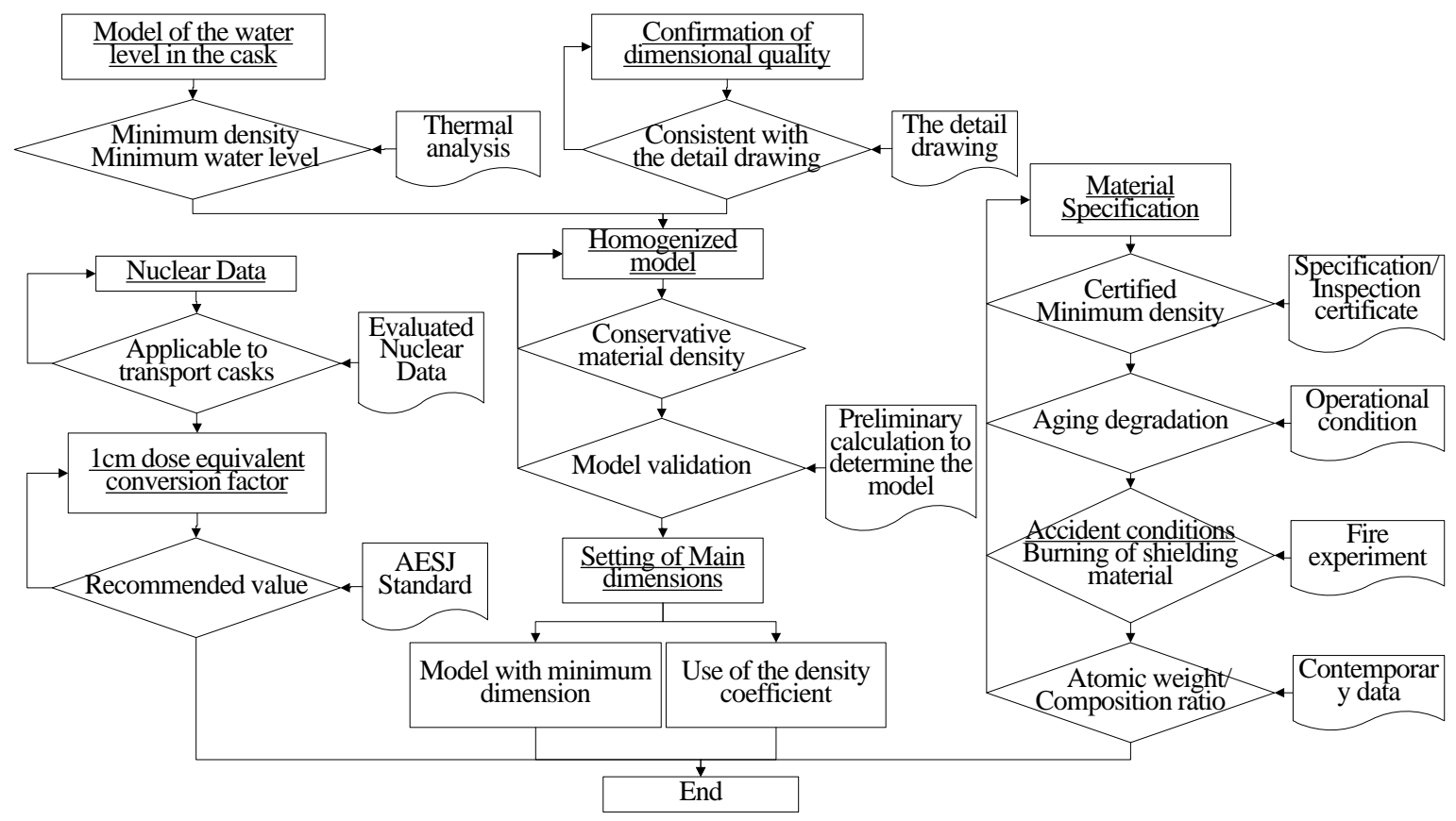

Figure 1. Modeling of geometric configuration of transport casks.

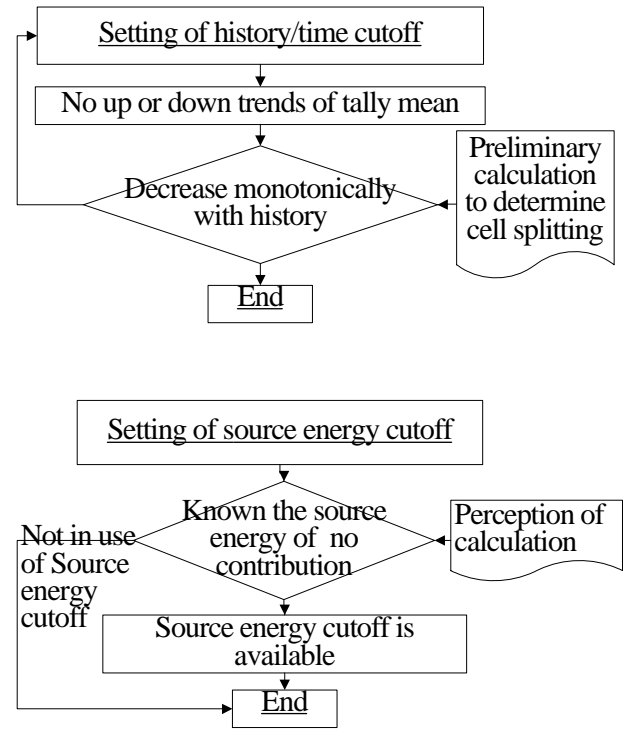

$\underline{\text { Truncation Cutoff }}$

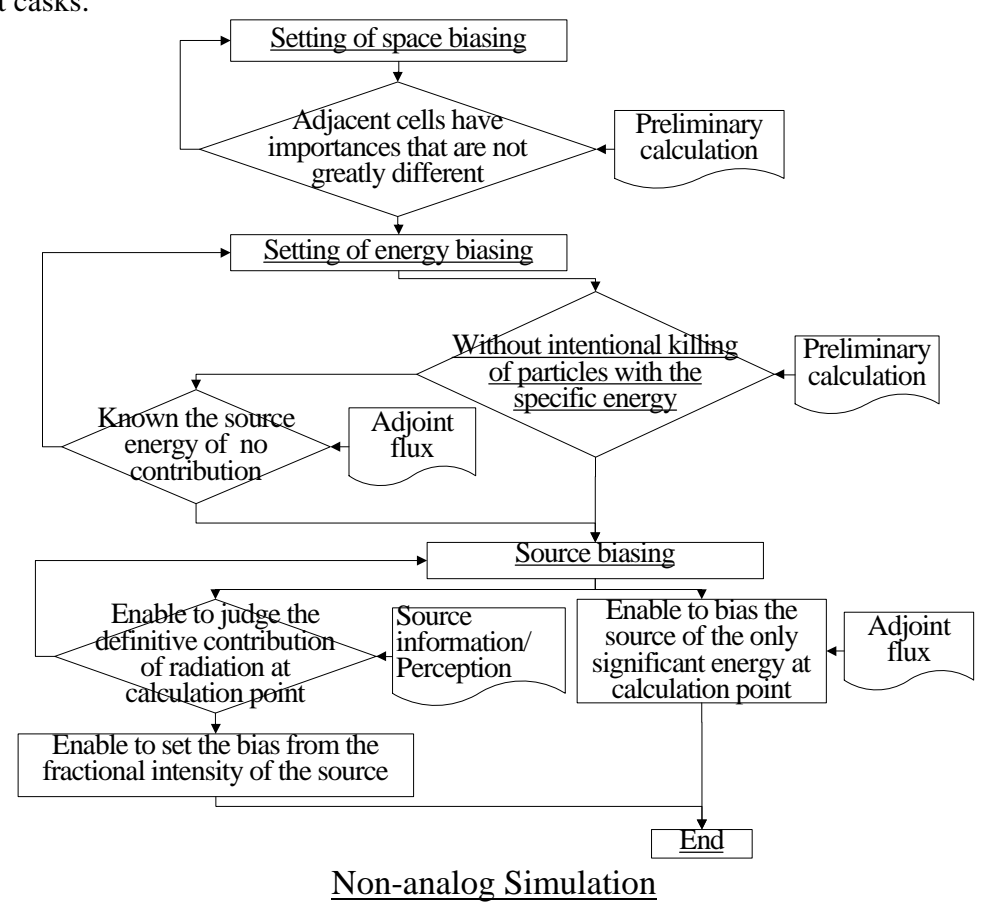

Non-analog Simulation

Figure 2. Approach in the use of the variance reduction techniques applicable to shielding configurations of transport casks. 


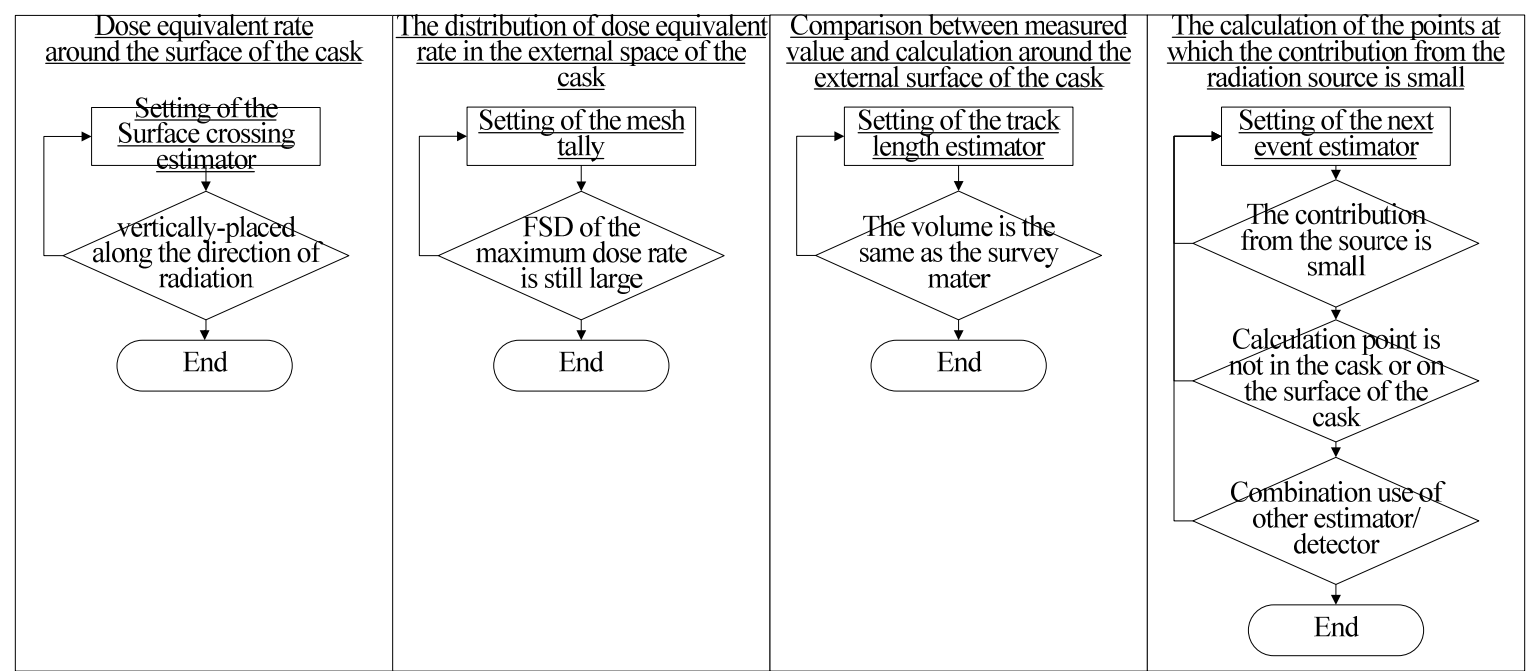

Figure 3. Approach in the use of the estimator (tally) applicable to shielding configurations of transport casks.

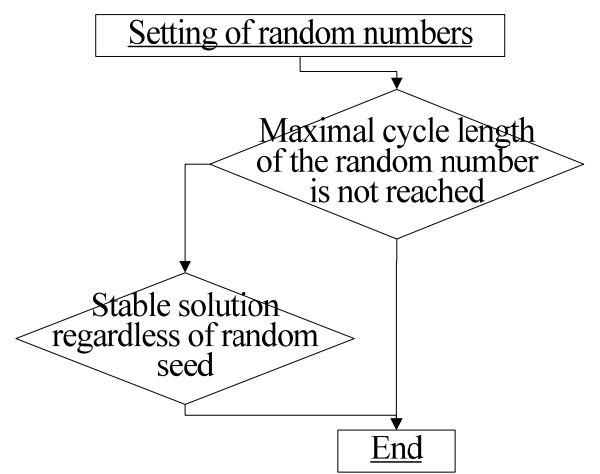

Figure 4. Approach in the quality of random number generator for Monte Carlo method.

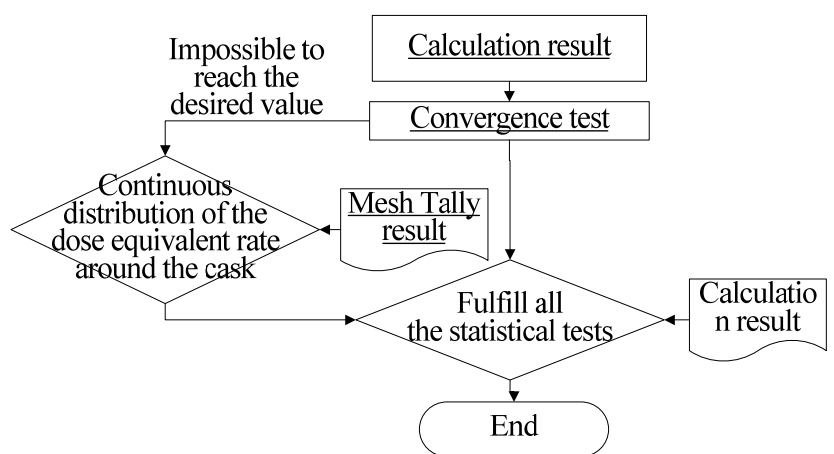

Figure 5. Approach in the evaluation of the calculation result and statistics.

\section{Conclusion}

In the present study, the guideline for radiation shielding evaluation of transport casks by Monte Carlo method was established. In this document, specific recommendations are made regarding radiation attenuation calculations, shielding design and standards of documentation. The guideline is expected to be used for the confirmation that effective shielding calculation has been performed and the result is verified.

\section{Future plan}

The Guideline for Radiation Shielding Evaluation of Transport Casks by Monte Carlo Method is scheduled for publication as Research report of National Maritime Research Institute, which is open to the public, within 2013.

\section{Acknowledgements}

This study was supported by the Budget for Nuclear Research of the Ministry of Education, Culture, Sports, Science and Technology. We would like to thank the special committee established under the Atomic Energy Society of Japan for their direction, dedication, and invaluable advice along this project.

\section{References}

[1] International Atomic Energy Agency, Regulations for the safe transport of radioactive material, 2005 edition, Safety Requirements No. TS-R-1, IAEA, Vienna, (2005).

[2] Subcommittee on Transport Packagings, the Nuclear Cycle Technical Committee and Standards Committee, Standard for Safety Design and Inspection of Shipping Casks for Spent Fuel, Fresh Mixed-Oxide Fuel and High Level Radioactive Waste: 2006, Atomic Energy Society of Japan, (2006). [in Japanese]

[3] E. E. Lewis and W. F. Miller Jr., Computational Methods of Neutron Transport, John Wiley \& Sons, New York, (1984), p.401. ISBN 0471092452 